\title{
Reseña de Atlas de Geografía Humana de España
}

\author{
Review of Atlas de Geografía Humana de España
}

\author{
Juan Ignacio Plaza Gutiérrez ${ }^{1}$ (1)
}
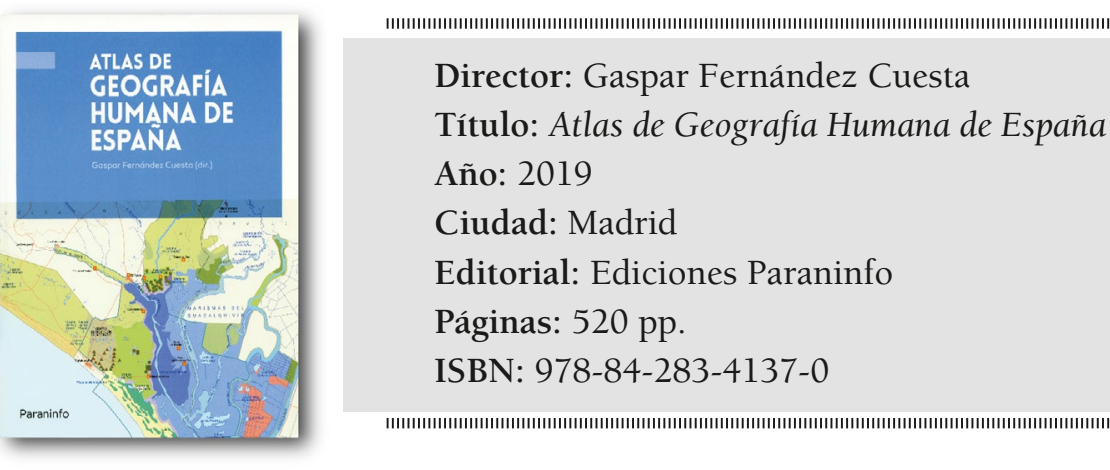

Director: Gaspar Fernández Cuesta

Título: Atlas de Geografía Humana de España

Año: 2019

Ciudad: Madrid

Editorial: Ediciones Paraninfo

Páginas: 520 pp.

ISBN: 978-84-283-4137-0

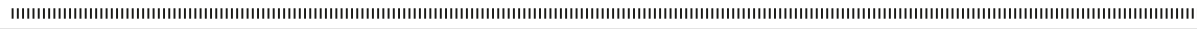

De muy reciente aparición, y casi coincidiendo en el tiempo con el Atlas Nacional de España del siglo XXI (ANEXXI), la publicación que bajo este título ahora se reseña es una obra colectiva, dirigida por Gaspar Fernández Cuesta (Universidad de Oviedo), pero en la que han participado doce autores, la mayor parte de ellos del estudio ovetense (9), a los que se unen dos de la Universidad de Valladolid y uno de la de Sevilla. El producto: una obra coral muy bien orquestada, perfectamente dirigida, magistralmente interpretada. Lleva marcado, como seña de identidad perfectamente distinguible, el sello de calidad cartográfica propio de la escuela del Departamento de Geografía de la Universidad de Oviedo, en la que pervive la impronta y el magisterio creados por el profesor Quirós, fallecido hace ahora un año, que supo imprimir a sus discípulos la preocupación y el rigor por el trabajo bien hecho, especialmente por la representación gráfica y cartográfica. De esta calidad ya han dado sobradas muestras tanto en la sólida revista que allí se edita desde 1980 y que cuatro décadas después ha sobrepasado ya el centenar de números, como en las muy diversas publicaciones de sus miembros. No puede olvidarse, en este sentido, la acendrada tradición investigadora que precede al libro que ahora se reseña en estas páginas y que da muestra de la sobrada capacidad que han ido adquiriendo sus autores desde hace ya tiempo para llevar a cabo publicaciones como ésta. Ahí están, por ejemplo, el Atlas social de las mujeres asturianas, publicado ya hace 25 años (en 1994) por el Servicio de Publicaciones del Principado de Asturias; el Atlas industrial de España: desequilibrios territoriales y localización de la industria (Ed. Nobel, 1999); el Atlas escolar de Asturias (Ed. Nobel, 2005); el Atlas aéreo de Asturias: los paisajes del siglo XX (Ed. Prensa Asturiana, 2001); o el Atlas temático de España (Ed. Nobel, 2010, 4 volúmenes), como referencias más destacadas, codirigidas casi todas ellas por los profesores Quirós Linares, Fernández Cuesta y Fernández García. La representación cartográfica, la fotografía aérea como herramienta de investigación y análisis, el estudio de los paisajes, el detenido seguimiento y observación de la evolución y transformaciones del territorio: tales son los ejes fundamentales sobre los que gravita este rigor analítico y este estudio bien hecho, serio y profundo, que acredita a los autores del Atlas de Geografía Humana de España y que traza su

1 Departamento de Geografía, Universidad de Salamanca, España. jip@usal.es 
perfil más significativo y que mejor les define. No en vano, dos son los principales grupos de trabajo en torno a los que se realiza toda esta labor en el Departamento de Geografía de la Universidad de Oviedo: el grupo "Análisis y representación de los paisajes geográficos españoles" (ARPE) y el "Observatorio del Territorio", contando este último con un potente archivo de fotografía aérea, el de su fototeca digital.

Estas son las mimbres con las que se ha entretejido el Atlas de Geografía Humana de España recientemente publicado y que antes de presentar la nómina de autores cuenta con una emotiva y muy afectiva dedicatoria al profesor José Ramón Fernández Prieto, "Pin", que tantas horas de trabajo, ratos y conversaciones de todo tipo y publicaciones compartió con ellos - como las reseñadas en líneas anteriores-y que falleció en fechas recientes. Alcanzando las 500 páginas —así pues....un Atlas denso-, su estructura se inicia con una necesaria introducción de 4 páginas, a la que siguen 5 partes que albergan entre todas 15 capítulos. Se completa con un apartado bibliográfico muy prolijo (22 páginas que reúnen 929 referencias o citas) y de fuentes (50 referencias de fuentes on-line). Cierra el Atlas un índice de topónimos (que aclara la naturaleza de los mismos y las páginas en las que se localizan dentro del libro) muy detallado, que ocupa 15 páginas y que integra 1.583 topónimos: el $85,5 \%$ de los mismos son de lugares y de unidades administrativas (casi tres cuartas partes de ellos, 1.160, son de entidades de población, 114 de comarcas, los 50 de todas las provincias, 19 de Comunidades Autónomas —las 17 más las dos Ciudades Autónomas de Ceuta y Melilla-, 7 de municipios y 5 de regiones históricas). El resto son topónimos del medio físico (172, la mayor parte son de ríos - 100-, acompañados de los de sierras - 39-, lagos y lagunas - 12-, islas - 11cabos - 4- y golfos -2-) y otros sin clasificar (hasta 56), pero que aluden a denominaciones y/o lugares muy precisos (desde Andalucía Oriental hasta algunos macizos montañosos, determinadas alineaciones como las Subbéticas, o algunos picos más elevados, pasando por sitios muy concretos como Arribes del Duero, Caldera de Taburiente, o Despeñaperros).

El Atlas es una obra muy bien complementada, con un texto muy adecuadamente presentado y estructurado, combinado con lo que es la esencia de una publicación de esta naturaleza: la cartografía, acompañada además, como se ha recordado, de un gran aparato estadístico, gráfico y fotográfico. Se nos presenta en un formato que, por su compo- sición, maquetación y formato recuerda mucho a los libros de texto del bachillerato. La redacción y presentación de los textos de los 15 capítulos es muy atractiva, didáctica y sugerente para su lectura y consulta, separando las ideas y cuestiones tratadas mediante guiones y flechas, con una estructura de apartados y subapartados muy pedagógica. Las cinco partes en las que se divide el Atlas se centran en los siguientes temas: España como ente geográfico y político-administrativo (parte I), dentro de la que se integran los capítulos 1 (España en el mundo y en Europa) y 2 (la organización políticoadministrativa de España); los recursos territoriales (parte II), que abarca los capítulos 3 (aguas continentales y red hidrográfica), 4 (recursos minerales, forestales, cinegéticos y pesqueros) y 5 (recursos turísticos, donde se incluyen también los espacios naturales protegidos); población e infraestructuras de transporte (parte III), cada uno de cuyos componentes ocupa un capítulo (población el 6 y redes de transporte el 7); actividades y espacios económicos (parte IV), que abarca cuatro capítulos: el 8 (actividades agroganaderas y espacios agrarios), el 9 (paisajes agrarios), el 10 (la industria y sus espacios) y el 11 (las actividades terciarias y sus espacios); finalmente, la última parte, la $\mathrm{V}$, tiene como objetivo central las ciudades y los espacios urbanos (el 12 trata de la formación del sistema urbano, el 13 de la ciudad preindustrial y el 14 de la ciudad industrial), aunque el último de los capítulos que se incluyen (el 15) se dedica a los desequilibrios territoriales.

El texto, sin embargo, ofrece una desigual extensión. Está más sesgado hacia las dos últimas partes (IV y V), ocupando cada una de ellas más de 100 páginas y representando entre ambas algo más de dos tercios del total de la obra (295 páginas, un $68 \%$ de todo el Atlas, alcanzando dimensiones más grandes en la parte dedicada a las actividades y espacios económicos - 180 páginas, un 41,5\% de toda la publicación-, especialmente los capítulos 8 y 10). En el extremo contrario, la parte I se queda tan solo en 19 páginas, aun agrupando dos capítulos. Es a partir de la parte III donde los capítulos comienzan a tener una extensión ya algo más grande que en los de las dos primeras: por el orden que se indica a continuación, son los capítulos 10, 8 y 14 los que más extensión tienen (superior a las 50 páginas), mientras que el $1,2,3$ y 5 no llegan a las 15 ninguno. Por otro lado, parece algo forzada la inclusión del último capítulo del Atlas, el 15, donde está, en la parte V, que temáticamente se dedica al mundo y espacio urbanos, pues el objeto central de tal capítulo es 
el de los desequilibrios territoriales. Con todo, el desarrollo del texto es bastante completo, incluso denso. No es este el caso de obras donde el texto simplemente va complementando toda la parte cartográfica y gráfica, sino más bien lo contrario, un verdadero compendio sobre la Geografía Humana de España redactado a conciencia y con profundidad, rigor y mucho contenido.

El conjunto del material no escrito, pero de sustancial importancia en la realización de un Atlas como este que ahora se reseña, se distribuye entre 70 cuadros, 169 mapas, 240 gráficos y 108 fotografías. Los cuadros están muy repartidos, pero un tercio de ellos se concentran en los capítulos 6 y 7 , en la parte III, dedicada a la población y las infraestructuras de transporte. Parece lógico especialmente pensando en el tema de población, donde los datos, las estadísticas, son una herramienta de trabajo fundamental. Respecto a los 169 mapas (prácticamente 1 mapa por cada dos páginas y media), algo más de la mitad (52\%) se localizan en dos capítulos: en el 8 (actividades agroganaderas y espacios agrarios, que es también uno de los tres más extensos de texto, con 46 mapas, algo más de una cuarta parte del total) y en el 6 (el dedicado a la población y que igualmente era uno de los que reunía más cuadros). Los gráficos, por su parte, son los que más abundan: 240. La mayor parte de ellos son planos de distintos temas; 122 (la mitad de todos los gráficos y casi dos tercios de todos los planos) son de ciudades, reunidos en los capítulos 12, 13 y 14, mientras que un tercio de los gráficos se concentran en los capítulos 6,7 y 10 - dedicados a la población, las infraestructuras y la industria-. Finalmente, de las 108 fotografías que contiene el Atlas la mitad se localizan en el capítulo 9 , que trata de los paisajes agrarios, lo cual tiene su lógica, aunque realmente casi todas ellas lo hacen en tres capítulos: el 8, el 9 y el 11, siendo prácticamente una cuarta parte de todas ellas fotografías áereas, a las que acompañan 8 imágenes satélite y 75 fotografías normales.

Estamos, en definitiva, ante una publicación seria y rigurosa, actualizada, que es de obligada referencia y consulta tanto para profesores, como para estudiantes y personas que gusten de conocer y ampliar sus conocimientos sobre el espacio geográfico español, realizada con el marchamo de calidad de un equipo a quien le avala la solidez y el afán por el trabajo bien hecho. 